\title{
Effectiveness of Vaginal versus Intramuscular Progesterone for the Prevention of Preterm Delivery
}

\author{
Rabia Wajid, ${ }^{1}$ Maria Zafar, ${ }^{2}$ Fatima Waheed ${ }^{3}$
}

\begin{abstract}
Objective: The objective was to compare the effectiveness of vaginal versus intramuscular progesterone to prevent preterm delivery in patients with history of preterm labor in previous pregnancy.

Patients and Methods: It was a Randomized Control Trial carried out in the Gynecology Unit in a Public sector Hospital, Lahore from March to December 2015. A total of 800 patients were enrolled through Antenatal OPD and were randomly divided into two groups by draw method. In Group-A, patients were administered $200 \mathrm{mg}$ of vaginal progesterone pessary once daily and in Group-B $250 \mathrm{mg}$ of intramuscular progesterone was injected weekly. Treatment was continued until 37 completed weeks of gestation. The patients were followed up through their contact numbers and on routine follow up. This practice was abandoned if premature rupture of membranes occurred and the
\end{abstract}

${ }^{1}$ Senior Registrar, Department of Obstetrics \& Gynaecology, Lady Willingdon Hospital, Lahore

${ }^{2}$ Women Medical Officer, Department of Obstetrics \& Gynaecology, Lady Aitchison Hospital, Lahore

${ }^{3}$ Senior Registrar, Department of Obstetrics \& Gynaecology, Lady Willingdon Hospital, Lahore

Date of Submission: 29-3-2016

Date of $1^{\text {st }}$ Revision Received: 18-7-2016

Date of $2^{\text {nd }}$ Revision Received: 9-8-2016

Date of Acceptance for Publication: 8-11-2016

Conflict of Interest: None

Funding Source: None

\section{Contribution}

All Authors have contributed in Study Design, Data Collection, Data Analysis, Data Interpretation, Manuscript Writing and Approval. fetus was delivered before 37 weeks. All the parameters were recorded by the researcher on proforma. The data was analyzed using Statistical Package for the Social Sciences (SPSS) version 16.0. Chi Square test was applied to draw the comparison.

Results: The mean age of patients was $26.16 \pm 5.36$ years $(18$ - 35 years). The 296 patients were Para 1 , 290 were Para 2, 142 were Para 3, 51 were Para 4 and 21 females were Para 5. In all females, the mean gestational age at time of presentation was $22.00 \pm 1.47$ weeks, whereas, at time of delivery, mean gestational age was $36.05 \pm 2.38$ weeks. In vaginal progesterone group, the mean gestational age at time of delivery was $36.67 \pm 1.92$ weeks while in IM group, mean gestational age at time of delivery was $35.43 \pm 2.62$ weeks. The difference between both groups was statistically significant $(\mathrm{P}<0.05)$. Effectiveness (delivery $\geq 37$ weeks) was achieved in $379(47 \%)$ cases, out of which $228(57 \%)$ cases belonged to vaginal progesterone group and $151(37.8 \%)$ cases belonged to IM progesterone group $(\mathrm{P}<0.05)$. Post stratification with age and parity also showed that vaginal progesterone is more efficacious than IM progesterone $(\mathrm{P}<0.05)$.

Conclusion: We concluded that vaginal progesterone is more effective than intramuscular progesterone for the prevention of preterm labor in patients with history of preterm labor in previous pregnancy.

Keywords: Preterm labor, prevention, vaginal versus intramuscular progesterone, efficacy.

\section{Introduction}

Preterm labor (PTL) is the leading cause of adverse perinatal outcome and strongly associated with far reaching consequences. The incidence of this problem is rising and is seen in around $15 \%$ of pregnancies in the developed world. ${ }^{1-3}$ 
The diagnosis of preterm labor rests upon presence of regular painful uterine contractions resulting in detectable cervical change. Unless there is a strong proof that labor is well established, there is a tendency to over diagnose. ${ }^{4}$

Progesterone was first identified in 1934, and its role in keeping uterus dormant was recognized in $1954 .{ }^{5}$ In the recent past, many studies evaluating the effect of either intramuscular or natural progesterone given by vaginal or oral route for prevention of preterm birth (PTB) are seen in the literature.Two recent trials by El-Gharib MN and Maher MA, about prevention of preterm delivery, show different results in terms of superiority of one type of progesterone over the other. ${ }^{6,7}$

The world over, preterm birth rate has been calculated to be around 11 percent in European region to 18 percent in Africa and about $12 \%$ in America. About 15 million preterm deliveries take place per annum, making it more essential to study the role of progesterone in preterm labour. ${ }^{8,9}$

The four fundamental processes initiating preterm contractions are stimulation of fetomaternal hypothalamic-pituitary-adrenal axis, anxiety of the mother or fetal stress, hemorrhage and over expansion of the uterus. The new research, incorporates factors such as progesterone withdrawal, and absence of changes in the spiral vessels, along with abruption and uterine and placental inadequecy. ${ }^{10}$

Maternal age and genetic disposition to preterm birth is also a contributor. African-American lineage is linked with an increased risk. The epidemiological factors also play their role. In a study preterm birth was seen more in nonwhite couples as compared to couples where father and mother were white..$^{11-13}$

There is a less of a possibility of preterm birth in women who has symptoms if cervix is $>30 \mathrm{~mm}$ long, ${ }^{14}$ and more possible if cervical length is less than $15 \mathrm{~mm} .{ }^{15}$ In two studies of women presenting with threatened preterm labor, high probability of delivery in 7 days was noticed if cervical length was less than $15 \mathrm{~mm} .{ }^{16}$ Women with history of preterm labor have higher rates of recurrence as compared to those who don't have any prior history i.e. $22 \%$ vs. $9 \% .^{15-17}$

Progesterone is generated by the corpus luteum in early pregnancy. Progesterone is crucial for pregnancy continuation until the placenta becomes responsible for this job. Progesterone is pivotal in for uterine quiescence late in the pregnancy due to its anti-inflammatory action. Withdrawal of progesterone action at uterine level takes place close to the start of labor, without much change in serum progesterone levels. Progesterone supplementation may enhance these actions, which take place through progesterone-receptors. $^{18}$

The effectiveness of progesterone use for preterm birth prevention depends on proper choice of patient, type of progestin, formulation, dosage, and route of administration.

The common routes used for progesterone administration include the intramuscular, vaginal and oral routes.

Natural progesterone is given vaginally. The benefit of vaginal administration is its high bioavailability at the uterine level. It also has few systemic side effects like bloating, nausea, breast tenderness, drowsiness and irritability, but causes vaginal irritation and requires daily usage. 17-alpha-hydroxyprogesterone caproate (17OHPC) is a synthetic progestogen given intramuscularly. The side effects include breast tenderness, acne, nausea, drowsiness or dizziness. Doses range from $25 \mathrm{mg}$ every five days to 1 gram per week.

In two studies conducted in 2012 and 2013 respectively, the samples of intramuscular progesterone were analyzed and approved throughout the United States. The FDA concluded that progesterone vaginal gel was not as much effective as placebo in reducing preterm births before 33 weeks of gestation among women with a shortened cervix but its use was safe..$^{19,20}$

The rationale of this study is to draw a comparison between the intramuscular and vaginal progesterone in our setup and establish which type is more efficacious in prevention of preterm labor in those with previous history of preterm Labor.

\section{Patients and Methods}

The effectiveness was considered if pregnancy is prolonged up to 37 completed weeks of gestation. Progesterone was administered in the form of 17-alpha-s Hydroxyprogesterone Caproate, $250 \mathrm{mg}$ weekly. An intramuscular injection was given into gluteal muscle. Vaginal progesterone was given as a $100 \mathrm{mg}$ vaginal pessary on daily basis. Study was carried out in the Department of Obstetrics \& Gynecology, in a Public Sector Hospital. It was non-probability purposive sampling and interventional study. The calculated sample size was 400 cases in each group, with 5\% level of significance, $80 \%$ power of study, taking expected percentage $20 \%$ in vaginal progesterone and $27.5 \%$ with intramuscular group. ${ }^{7}$ It was conducted during 
March 2015 to December 2015. The following patients were included: age group $(18-35 \mathrm{yrs})$. The patients with (18 - 15 years) with $20-24$ weeks of gestation (on dating scan) with prior history of preterm delivery (on history and medical record) and Parity up to 5.

The exclusion criteria was twin gestation (on USG), intrauterine Fetal demise(On USG), anomalous baby (On USG),severe medical disorders like chronic liver disease (deranged Liver Function Tests), renal disease (Serum Creatinine greater than $2.5 \mathrm{mg} / \mathrm{dl}$ ), previous history of deep venous thrombosis).

All patients after fulfilling the inclusion and exclusion criteria were enrolled through Antenatal OPD. After taking informed consent of the patients undergoing trial and approval of hospital ethical committee, patients were randomly allocated into two equal groups by Draw method. Draw was made for group A and group B. First patient was asked to pick one draw and included in respective group (i.e. A or B) and then respectively in A or B groups, so a random allocation of the patients into two groups was ensured.

In Group-A, patients were administered 200mg of vaginal progesterone pessary once daily and in GroupB $250 \mathrm{mg}$ of intramuscular progesterone was injected weekly. The treatment was continued until 37 completed weeks of gestation in case of continuation of pregnancy. The patients were followed up through their contact numbers or at the routine follow up visit. The telephonic follow-up was used to minimize dropout rate. Therapy was discontinued if premature rupture of membranes occurred and the fetus was delivered before 37 weeks. The duration of gestation and frequency of efficacy of the drugs was calculated and recorded by the researcher herself on a pre-designed proforma. There was no drop out cases.

The data analysis was done using computer software for data analysis named Statistical Package for the Social Sciences (SPSS) version 16.0. Mean and standard deviation was calculated for quantitative variables like age and duration of gestation in both groups. Frequency and percentages were calculated for quailtative variable i.e. efficacy of the drugs. Chi square test was applied to compare both groups for the efficacy. P-Value $\leq 0.5$ was considered as significant. Effect modifiers were controlled through exclusion criteria. Stratification for age and parity was done to control further effect modifiers. Frequency was calculated for parity. Chi-square test was applied post stratification.

\section{Results}

A total of 800 cases (400 in each group) were recruited in the study with the mean age of $26.16 \pm 5.36$ years. The age of the patients ranged between 18 to 25 years. The mean age of patients in the vaginal progesterone group was $26.30 \pm 5.40$ years. The mean age of patients in the IM progesterone group was $26.02 \pm 5.32$ years (Table 1). 296 patients were Para 1, 290 were Para 2, 142 were Para 3, 51 were Para 4 and 21 females were Para 5 (Fig. 1). In all females, the mean gestational age at time of presentation was $22.00 \pm 1.47$ weeks. After administration of progesterone therapy (whether vaginal or IM), the gestational age at time of delivery was $36.05 \pm 2.38$ weeks which was significantly different $(\mathrm{p}<0.05)$ (Table 2$)$. In vaginal progesterone group, the mean gestational age at time of presentation was $21.95 \pm 1.47$ weeks which was significantly increased to $36.67 \pm 1.92$ weeks at time of delivery $(\mathrm{p}<0.05)$. Similarly, in IM group, mean gestational age at time of presentation was $22.06 \pm 1.48$ weeks which was significantly increased to $35.43 \pm$ 2.62 weeks at time of delivery $(\mathrm{p}<0.05)$. But the gestational age was closer to term in vaginal group. (Table 3). When both groups were compared for mean gestational age at time of presentation, it was noticed that in vaginal progesterone group, the mean gestational age at time of presentation was $21.95 \pm 1.47$ weeks while in IM group, mean gestational age at time of presentation was $22.06 \pm 1.48$ weeks. The difference between both groups was insignificant $(\mathrm{p}>$ $0.05)$. When both groups were compared for mean gestational age at time of delivery, it was noticed that in vaginal progesterone group, the mean gestational age at time of delivery was $36.67 \pm 1.92$ weeks while in IM group it was $35.43 \pm 2.62$ weeks. The difference between both groups was statistically significant ( $\mathrm{p}<$ 0.05 ). Effectiveness (delivery $\geq 37$ weeks) was achieved in $379(47 \%)$ cases while could not be achieved (delivery before term) in $421(53 \%)$ cases (Fig. 2). In vaginal progesterone group, efficacy was achieved in $228(57 \%)$ cases while in IM progesterone group; effectiveness was achieved in 151 (37.8\%) cases. There was significant difference observed between both study groups and vaginal progesterone has more effectiveness as compared to IM progesterone (Table 4). We stratified data according to different age groups. In females of age $18-25$ years, with vaginal progesterone, effectiveness was achieved in $102(54.5 \%)$ cases while with IM progesterone in $75(39.9 \%)$ cases. In females of age 26 - 35 years, with vaginal progeste- 
rone, effectiveness was achieved in $126(59.2 \%)$ cases while with IM progesterone in $76(35.8 \%)$ cases. There was significant difference observed between both study groups in any age and vaginal progesterone has more efficacy as compared to IM progesterone. We stratified data according to different age groups. In females with parity $1-3$, with vaginal progesterone, efficacy was achieved in $201(55.8 \%)$ cases while with IM progesterone in 138 (37.5\%) cases. In females with parity $4-5$, with vaginal progesterone, efficacy was achieved in $27(67.5 \%)$ cases while with IM progesterone in $13(40.6 \%)$ cases. There was considerable difference observed between both study groups with any parity and vaginal progesterone has more efficacy as compared to IM progesterone.

Table 1: Descriptive statistics of age of patients in both study groups.

\begin{tabular}{|l|l|c|c|}
\hline & & \multicolumn{2}{|c|}{ Study Group } \\
\hline & & Group A & Group B \\
\hline & $\mathrm{N}$ & 400 & 400 \\
\hline \multirow{2}{*}{ Age (years) } & Mean & 26.30 & 26.02 \\
\cline { 2 - 4 } & SD & 5.40 & 5.32 \\
\hline & Minimum & 18 & 18 \\
\hline & Maximum & 35 & 35 \\
\hline
\end{tabular}

Table 2: Comparison of gestational age at time of presentation and delivery.

\begin{tabular}{|l|c|c|}
\hline & $\begin{array}{c}\text { Gestational Age at } \\
\text { Presentation }\end{array}$ & $\begin{array}{c}\text { Gestational Age at } \\
\text { Delivery }\end{array}$ \\
\hline $\mathrm{N}$ & 800 & 800 \\
\hline Mean & 22.00 & 36.05 \\
\hline SD & 1.47 & 2.38 \\
\hline
\end{tabular}

Paired $\mathrm{t}$-test $=299.567 \mathrm{p}$-value $=0.000$ (Significant) 7

\section{Discussion}

Preterm birth is a leading cause of adverse perinatal outcome as well as that of $80 \%$ of neonatal deaths. Prematurity is a reason for $50 \%$ of long term morbidity in the surviving infants. Preterm birth rates have escalated over the last thirty years. Preterm birth is seen in $9.6 \%$ of cases globally, most of them in underdevelo- ped nations. Although there are many ways to prevent this alarming problem, none of them is effective. Upcoming research has indicated that progesterone supplementation is helpful in this regard. The safety and efficacy of progestogens are related to individual pharmacologic properties of each drug.

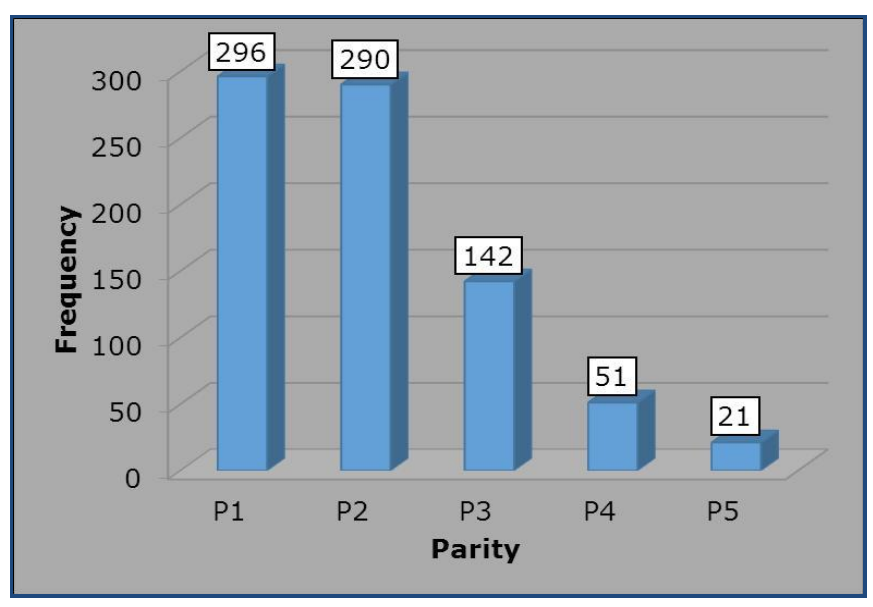

Fig. 1: Distribution of Parity of Patients.

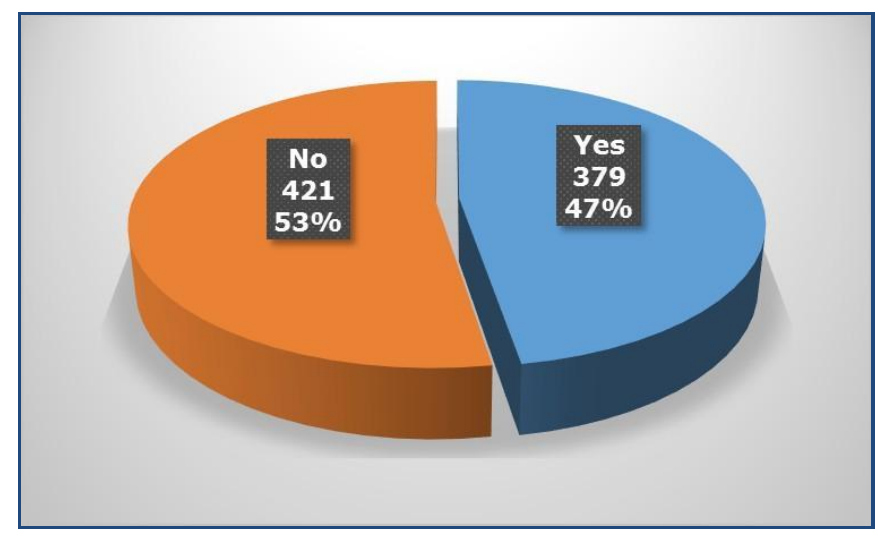

Fig. 2: Distribution of Efficacy Achieved.

There are few studies available in the literature which addresses the ideal route for progesterone administration in women with prior history of preterm birth and even no local studies address the comparison between the vaginal and the intramuscular progesterone. This study is an effort to evaluate the best route of progesterone administration for the prevention of preterm birth and the available options include the intramuscular and the vaginal progesterone. ${ }^{20}$

The findings of our study are in agreement with Maher MA who assessed the effectiveness both types 
of progesterone in reduction of recurrent preterm birth before 34 weeks of pregnancy. They concluded that the baseline features of the patients were similar. i.e. $(94.1 \%)$ patients in the vaginal group and $(90.8 \%)$ patients in the intramuscular group took their medication regularly. Vaginal progesterone group had less number of deliveries before 34 weeks of gestation than the intramuscular preparation. The same was seen at 28 and 32 weeks of gestation. So the results were agreement with our study that vaginal progesterone was more effective for the prevention of preterm birth with very few side effects. ${ }^{7}$

El-Gharib MN and others drew a comparison between the vaginal and intramuscular groups to prevent preterm labor in women with single fetus at risk of premature birth and found less cases of preterm delivery in the vaginal group. More side effects were seen in the intramuscular group. So once again the results of our study matched this study. ${ }^{6}$

The study conducted by Azza and colleagues showed results which did not match our study. There were less cases of preterm labor at 34 and 37 weeks in the intramuscular group as compared to the other group. ${ }^{21}$ It was a prospective comparative clinical trial having a smaller sample size as compared to our study.

The results of the OPPTIMUM Trial, the largest trial to date found no benefit of use of vaginal progesterone for prevention of preterm birth. Although no comparison was made with the intramuscular progesterone, this result is also contrary to the findings proving vaginal route as more effective in our study. ${ }^{22}$

\section{Conclusion}

We concluded that vaginal progesterone is much more effective than progesterone injected intramuscularly for the prevention of preterm labor in patients with history of preterm birth.

\section{References}

1. Goldenberg RL, Culhane JF, Iams JD, Romero R. Epidemiology and causes of preterm birth. Lancet, 2008; 371: 75-84.

2. Moster D, Lie RT, Markestad T. Long-term medical and social consequences of preterm birth. $\mathrm{N}$ Engl $\mathrm{J}$ Med. 2008; 359: 262-73.

3. Azza A, Abd El Hameed. Vaginal versus intramuscular progesterone in the prevention of preterm labour and their effect on uterine and fetal blood flow. Middle East Fertility Society Journal 2012; 17: 163-9.

4. Chao TT, Bloom SL, Mitchell JS. The diagnosis and natural history of false preterm labor. Obstet Gynecology 2011; 118: 1301.

5. Berghella V. Progesterone and preterm birth prevention: translating clinical trials data into clinical practice. Am J Obstet Gynecology 2012; 206: 376-86.

6. El-Gharib MN, El-Hawary TM. Matched sample comparison of intramuscular versus vaginal micronized progesterone for prevention of preterm birth. J Matern Fetal Neonatal Med. 2013; 26: 716-9.

7. Maher MA, Abdelaziz A, Ellaithy M, Bazeed MF. Prevention of preterm birth: a randomized trial of vaginal compared with intramuscular progesterone. Acta Obstet Gynecol Scand. 2013; 92: 215-22.

8. Lawn JE, Gravett MG, Nunes TM. Global report on preterm birth and stillbirth (1 of 7): definitions, description of the burden and opportunities to improve data. BMC Pregnancy Childbirth 2010; 10 Suppl. 1: S1.

9. Blencowe H, Cousens S, Oestergaard MZ. National, regional, and worldwide estimates of preterm birth rates in the year 2010 with time trends since 1990 for sele- 
cted countries: a systematic analysis and implications. Lancet 2012; 379: 2162.

10. McMaster-Fay RA. Failure of physiologic transformation of the spiral arteries of the uteroplacental circulation in patients with preterm labor and intact membranes. Am J Obstet Gynecol. 2004; 191: 1837?

11. Romero R, Kusanovic JP, Chaiworapongsa T, Hassan SS. Placental bed disorders in preterm labor, preterm PROM, spontaneous abortion and abruptio placentae. Best Pract Res Clin Obstet Gynaecol. 2011; 25: 313.

12. Genc MR, Onderdonk A. Endogenous bacterial flora in pregnant women and the influence of maternal genetic variation. BJOG. 2011; 118: 154.

13. Srinivasjois RM, Shah S, Shah PS, Knowledge Synthesis Group on Determinants of Preterm/LBW Births. Biracial couples and adverse birth outcomes: a systematic review and meta-analyses. Acta Obstet Gynecol Scand. 2012; 91: 1134.

14. Iams JD. Prediction and early detection of preterm labor. Obstet Gynecol. 2003; 101: 402.

15. Sotiriadis A, Papatheodorou S, Kavvadias A, Makrydimas G. Transvaginal cervical length measurement for prediction of preterm birth in women with threatened preterm labor: a meta-analysis. Ultrasound Obstet Gynecol. 2010; 35: 54.

16. Kumar D, Springel E, Moore RM, et al. Progesterone inhibits in vitro fetal membrane weakening. Am J Obs- tet Gynecol. 2015; 213: 520.e1.

17. O'Brien JM, Lewis DF. Prevention of preterm birth with vaginal progesterone or 17-alpha-hydroxyprogesterone caproate: a critical examination of efficacy and safety. Am J Obstet Gynecol. 2016; 214: 45.

18. Chang J, Zhao Y, Zhao W. Quality assessment of compounded 17-hydroxyprogesterone caproate. Am J Obstet Gynecol. 2014; 210: 47.e1.

19. Yazdani T, Karim F, Younas M. Prophylaxis of Preterm labor with Hydroxyprogesterone Caproate in High risk cases: A pearl for Obstetricians. JSOGP. 2015; 5 (1): 25-28.

20. Hassan SS, Romero R, Vidyadhari D. Vaginal progesterone reduces the rate of preterm birth in women with a sonographic short cervix: a multicenter, randomized double-blind, placebo-controlled trial. Ultrasound Obstet Gynecol. 2011; 38: 18.

21. Azra A, Abd El Hameed .Vaginal versus Intramuscular Progesterone in the Prevention of Preterm labour and their effect on Uterine and Fetal blood flow.Middle East Fertility Society Journal 2012; 17: 16.

22. Norman JE, Marlow N, Shennan A, Bennet PR, Thornton S, Robson SC, Petrou S. Vaginal progesterone prophylaxis for preterm birth (the OPPTIMUM Study): a multi centre, randomized, double blind trial. Lancet 2016; 387: 2106-2116. 